\title{
Originals
}

\section{The Effect of Acetylsalicylic Acid on Insulin Response to Glucose and Arginine in Normal Man}

\author{
D. Giugliano, R. Torella, N. Siniscalchi, L. Improta, and F. D'Onofrio \\ Institute of Medical Pathology and Clinical Methodology, I Faculty of Medicine, University of Naples, Naples, Italy
}

\begin{abstract}
Summary. In 14 normal subjects, treatment with acetylsalicylic acid (ASA, $3.2 \mathrm{~g}$ daily for 3 days) a well known inhibitor of prostaglandin synthesis, caused a slight but significant decrease $(p<0.05)$ in basal plasma glucose levels; by contrast, basal insulin rose from $5 \pm 1$ to $8 \pm 1 \mu \mathrm{U} / \mathrm{ml}(\mathrm{p}<0.01)$ after ASA. Pretreatment with ASA augmented the early insulin response to a standard IV glucose tolerance test $(25 \mathrm{~g})$ in 7 normal subjects $(\mathrm{p}<0.05$ at $2 \mathrm{~min}$; $p<0.02$ at $5 \mathrm{~min} ; \mathrm{p}<0.01$ at $10 \mathrm{~min}$ ). No significant changes were detected in the rate of glucose utilization. 7 additional subjects received a standard arginine test without and with ASA pretreatment. Arginine stimulated insulin levels were increased after ASA $(p<0.01$ at $15 \mathrm{~min} ; \mathrm{p}<0.05$ at $30 \mathrm{~min}$; $p<0.05$ at $45 \mathrm{~min}$ ), whereas glucose values were lower than under basal conditions at all times, with significant differences at $105(\mathrm{p}<0.02)$ and 120 $(\mathrm{p}<0.05)$ min. A possible role of prostaglandins upon the insulin responses to glucose and arginine is discussed.
\end{abstract}

Key words: Acetylsalicylic acid, glucose, insulin, intravenous glucose tolerance test, arginine test, prostaglandins.

It has been suggested that Prostaglandins (PGs) of the $E$ series may play some role in negatively modulating the insulin response to glucose in the anaesthetized dog [1] and in normal [2] and diabetic [3] subjects. Accordingly, in the present study we have investigated the effect of acetylsalicylic acid (ASA), a well-known inhibitor of PGs synthesis [4-5], on basal and glucose-stimulated insulin release and also on arginine-stimulated insulin secretion.

\section{Materials and Methods}

Informed consent was obtained from 14 healthy medical students after a full explanation of the purpose, nature and possible risks involved in the study. They were free from acute or chronic, metabolic or cardiovascular diseases at the time of the study and had no family history of diabetes. The sex, age, $\%$ idcal body weight, side effects during ASA treatment and serum ASA levels are given in Table 1. Each subject was instructed to eat a balanced diet with $250 \mathrm{~g}$ of carbohydrates/day during the entire study period. The weight of each subject remained stable.

The tests were carried out after an overnight fasting period $(12 \mathrm{~h})$ with the subjects supine. Indwelling teflon catheters were inserted in each antecubital vein, one for infusion, the other for blood sampling. Patency was preserved by a slow saline $(0.154 \mathrm{~mol} / \mathrm{l})$

Table 1. Characteristics of the subjects studied

\begin{tabular}{|c|c|c|c|c|c|c|}
\hline & Case & Sex & $\begin{array}{l}\text { Age } \\
y\end{array}$ & $\begin{array}{l}\% \text { Ideal } \\
\text { bodyweight }\end{array}$ & $\begin{array}{l}\text { Side } \\
\text { effects }\end{array}$ & $\begin{array}{l}\text { ASA levels } \\
\mathrm{mg} / 100 \mathrm{ml}\end{array}$ \\
\hline \multirow{7}{*}{ IVGTT } & 1 & $F$ & 23 & $103 \%$ & S. & 30 \\
\hline & 2 & $\mathbf{M}$ & 26 & $106 \%$ & F.T. & 25 \\
\hline & 3 & $\mathrm{~F}$ & 24 & $103 \%$ & $\mathrm{~T}$ & 20 \\
\hline & 4 & $\mathrm{~F}$ & 26 & $96 \%$ & - & 20 \\
\hline & 5 & $\mathbf{M}$ & 24 & $119 \%$ & - & 19 \\
\hline & 6 & $\mathrm{~F}$ & 24 & $88 \%$ & $\mathrm{~T}$ & 21 \\
\hline & 7 & $\mathrm{~F}$ & 22 & $94 \%$ & $\mathrm{~T}$ & 27 \\
\hline \multirow{7}{*}{$\begin{array}{l}\text { Arginine } \\
\text { test }\end{array}$} & 8 & $\mathrm{M}$ & 24 & $118 \%$ & S. P. & 17 \\
\hline & 9 & $\mathbf{F}$ & 24 & $105 \%$ & T. & 21 \\
\hline & 10 & $F$ & 30 & $92 \%$ & - & 18 \\
\hline & 11 & $\mathrm{M}$ & 27 & $100 \%$ & S. F. & 25 \\
\hline & 12 & M & 24 & $94 \%$ & F.T. & 21 \\
\hline & 13 & $\mathrm{M}$ & 24 & $118 \%$ & - & 16 \\
\hline & 14 & $\mathrm{~F}$ & 28 & $106 \%$ & T.P. & 24 \\
\hline
\end{tabular}

$\mathrm{S}=$ sleepiness $; \mathrm{F}=$ fatigue $; \mathrm{T}=$ tinnitus; $\mathbf{P}=$ Epigastric pain 

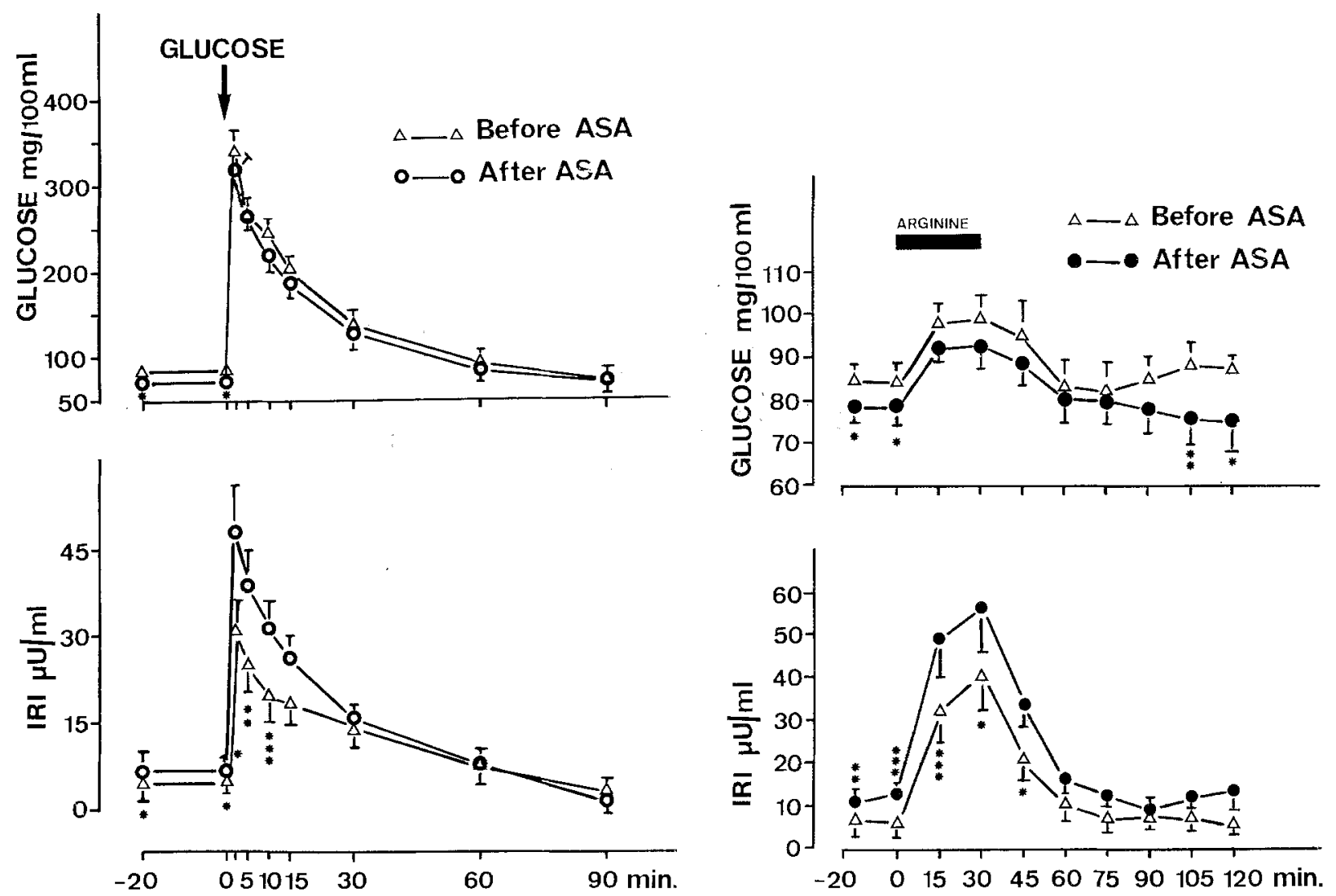

Fig. 1. Plasma glucose and insulin concentrations during the IVGTT before $(\Delta-\Delta)$ and after $(\bullet-\bullet)$ ASA treatment in 7 normal volunteers. Results are expressed as mean \pm SEM. ${ }^{*} \mathrm{p}<0.05 ; * * \mathrm{p}<0.02 ; * * \mathrm{p}<0.01$

drip. A group of 7 subjects received an intravenous glucose tolerance test (IVGTT-25 $\mathrm{g}$ of glucose injected in $2 \frac{1}{2} \mathrm{~min}$ ) with blood samples drawn in the basal state and 2, 5, 10, 15, 30, 60 and 90 min after the start of glucose load. The same subjects were submitted to another IVGTT after 3 days treatment with ASA (3.2 g daily divided into four doses). The remaining 7 subjects received an intravenous arginine test $(100 \mathrm{ml}$ of a $30 \%$ arginine monochloride solution infused over a period of $30 \mathrm{~min}$ ) before and after 3 days treatment with ASA, with blood samples drawn every 15 min after the start of the test until the 120th min.

Blood specimens were collected in prechilled tubes containing $1.2 \mathrm{mg}$ of EDTA per ml of blood, centrifuged at $4{ }^{\circ} \mathrm{C}$ and the plasma separated and frozen at $-20^{\circ} \mathrm{C}$ until the time of analysis, not more than 4 weeks later. Plasma glucose was estimated according to Huggett and Nixon [6]; plasma insulin using a commercial radioimmunoassay kit. For insulin values greater than $5 \mu \mathrm{U} / \mathrm{ml}$, this assay has an intraassay coefficient of variation of $10 \%$ and an interassay coefficient of $20 \%$; the minimal sensitivity
Fig. 2. Plasma glucose and insulin concentration during the arginine test before $(\Delta-\Delta)$ and after $(\bullet-\bullet)$ ASA in 7 normal volunteers. Results are expressed as mean \pm SEM. * $p<0.05$; $* * \mathrm{p}<0.02 ; * * * \mathrm{p}<0.01$

of this assay using $0.1 \mathrm{ml}$ of plasma is $2 \mu \mathrm{U} / \mathrm{ml}$. All samples from one subject were analyzed in the same assay. Plasma ASA was measured according to Trinder [7]. Statistical analysis of results was performed using the paired $t$ test [8]. Glucose disappearance rate was calculated by the method of least squares, taking the natural logs of the glucose values from $15 \mathrm{~min}$ to $60 \mathrm{~min}$. Results are presented as mean \pm SEM.

\section{Results}

Treatment with $3.2 \mathrm{~g}$ ASA daily caused a slight but significant decrease in basal plasma glucose levels in all 14 subjects studied $(82 \pm 2 \mathrm{mg} / 100 \mathrm{ml}$ before vs $76 \pm 4 \mathrm{mg} / 100 \mathrm{ml}$ after ASA, $\mathrm{p}<0.05)$. By contrast, basal insulin rose from $5 \pm 1 \mu \mathrm{U} / \mathrm{ml}$ to $8 \pm 1 \mu \mathrm{U} / \mathrm{ml}$ $(p<0.01)$ after ASA.

As shown in Figure 1, no significant differences in the pattern of plasma glucose levels during the IVGTT was found after ASA treatment. Similarly, the glucose disappearance rate $\left(\mathrm{k}_{15-60}\right)$ was not mod- 
ified by aspirin administration $(1.91 \pm 0.25$ before vs $1.81 \pm 0.13$ after ASA). On the contrary, the insulin response to glucose was significantly augmented after ASA $\quad(55 \pm 14 \%$ increase, $p<0.05$, at $2 \mathrm{~min}$; $55 \pm 14 \%$ increase, $\mathrm{p}<0.02$, at $5 \mathrm{~min} ; 57 \pm 10 \%$ increase, $\mathrm{p}<0.01$, at $10 \mathrm{~min}$ ). After this time, no significant changes were recorded.

The pattern of plasma glucose and IRI levels detected during the arginine test before and after ASA, is shown in Figure 2. Glucose values were lower at all times after aspirin administration with significant differences at $105(\mathrm{p}<0.02)$ and 120 $(\mathrm{p}<0.05) \mathrm{min}$. By contrast, insulin levels were significantly increased by ASA $(33 \pm 7 \%$ increase, $\mathrm{p}<0.01$, at $15 \mathrm{~min} ; 30 \pm 10 \%$ increase, $\mathrm{p}<0.05$, at $30 \mathrm{~min} ; 24 \pm 10 \%$ increase, $\mathrm{p}<0.05$, at $45 \mathrm{~min}$ ).

Plasma ASA determination carried out in all the subjects, gave values within the range of pharmacological efficiency $(15-30 \mathrm{mg} / 100 \mathrm{ml})$.

\section{Discussion}

The results of this study clearly show that oral administration of ASA ( $3.2 \mathrm{~g}$ daily for 3 days) significantly increases the first phase of insulin secretion 2-10 min) in response to a standard IVGTT (25 g) and also augments arginine-induced insulin release in normal man. ASA itself causes a rise in basal insulin and decreases basal glucose levels.

Glucose utilization rate was not significantly modified despite the increased first phase insulin secretion induced by ASA; this fact may indicate that a maximal rate for the glucose load had already been achieved. By contrast, the increment in plasma glucose elicited by arginine was lower than under basal conditions, probably related to the augmented and sustained insulin levels induced by the drug.

Although it is well known that hypoglycaemia often accompanies ASA intoxication [9-10] and that salicylate compounds tend to decrease circulating blood glucose levels in normal and diabetic alike $(11-12)$, it is still unclear how salicylates exert their action. In in vitro studies ASA has been reported to increase glucose uptake by isolated rat diaphragm [13] and to enhance glucose oxidation by adipose tissue and rat diaphragm [14]. A decreased rate of glucose absorption from the bowel [15] and a marked reduction or disappearance of liver glycogen [16-17] have also been considered as causes of ASA hypoglycaemia. ASA is also a potent inhibitor of gluconeogenesis when tested in the isolated perfused rat liver [18]. Moreover, aspirin administration has been reported to enhance glucose peripheral uptake in normal subjects [19], although this finding is com- patible with the increased IRI levels induced by the drug.

Our results seem to favour this last concept that the decrease in glucose levels induced by ASA is to be regarded, at least in part, as a consequence of the augmented insulin concentrations. However, it must be stressed that other authors [20-21] have failed to observe any effect of salicylates on blood glucose in healthy persons.

Information regarding the effect of ASA upon insulin response to glucose and glucose utilization in normals, is sparse. In a recent abstract, Micossi et al. [22] found that the early insulin response to an IV glucose load $(5 \mathrm{~g})$ was augmented after ASA in normal subjects. Field et al. [23] reported that intravenous administration of glucose 2 hours after completion of a salicylate infusion was associated with improvement in glucose tolerance and an augmented plasma insulin response in normals and mild diabetics. On the contrary, no change in glucose disappearance rate was found in normal subjects receiving sodium salicylate which augmented acute insulin response to glucose [3] and no effect on glucose tolerance tests was seen in normals after ASA administration. Restoration of the acute insulin response to glucose and on improved rate of glucose utilization have also been demonstrated in diabetics during sodium salicylate infusion [3] or after ASA [22].

All these studies, however, provide no insight into the mechanisms of the salicylate effect on insulin secretion. Since we have shown that $\mathrm{PGE}_{1}$ significantly decreased the early insulin response $\left(2^{\prime}-15^{\prime}\right)$ to a standard IVGTT in normal man [2], and that ASA seems to have an opposite effect to $\mathrm{PGE}_{1}$ infusion upon insulin secretion, it can be speculated that aspirin acts via the inhibition of endogenous PGs synthesis [4-5]. Similar findings have been reported by Robertson with $\mathrm{PGE}_{2}$ [3]. On the other hand, the effect of ASA on insulin response to glucose and arginine could be unrelated to its effect on PGs synthesis.

Acknowledgments. We are indebted to Mr. Raffaele Ragone for the dosage of ASA.

\section{References}

1. Robertson, P.R., Gavareski, D. J., Porte, D., Jr., Bierman, E. L.: Inhibition of in vivo insulin secretion by prostaglandin $\mathrm{E}_{1}$. J. Clin. Invest. 54, 310-315 (1974)

2. Giugliano, D., Torella, R., Improta, L., D'Onofrio, F.: Effects of prostaglandin $E_{1}$ and prostaglandin $F_{2}$ on insulin and glucagon secretion during the intravenous glucose tolerance test in man. Diabete Metab. (In press) (1978) 
3. Robertson, P.R., Chen, M.: A role for prostaglandin E in defective insulin secretion and carbohydrate intolerance in diabetes mellitus. J. Clin. Invest. 60, 747-753 (1977)

4. Vane, J.R.: Inhibition of prostaglandin synthesis as a mechanism of action for aspirin-like drugs. Nature 231, 232-235 (1971)

5. Hamberg, M.: Inhibition of prostaglandin synthesis in man. Biochem. Biophys. Res. Commun. 49, 720-726 (1972)

6. Huggett, A.S.G., Nixon, D.A.: Use of glucose oxidase, peroxidase and o-dianisidine in the determination of blood and urinary glucose. Lancet 1957 II, 368-370

7. Trinder, P.: Rapid determination of salicylate in biological fluids. Biochem. J. 57, 301-303 (1954)

8. Snedecor, G. W.: Statistical methods. 5th edition. Ames, Iowa: The Iowa State University Press 1966

9. Cotton, E. K., Fahlberg, V.I.: Hypoglycaemia with salicylate poisoning. A report of two cases. Am. J. Dis. Child. 108, 171-173 (1964)

10. Barnett, H.L., Powers, J. R., Benward, J. H., Hartman, A. F.: Salicylate intoxication in infants and children. J. Pediatr. 21, 214-223 (1942)

11. Hecht, A., Goldner, M. G.: Reappraisal of the hypoglycaemic action of acetylsalicylate. Metabolism 8, 418-428 (1959)

12. Gilgore, S. G.: The influence of salicylate on hyperglycaemia. Diabetes 9, 392-395 (1960)

13. Randle, P.J., Smith, G.H.: Regulation of glucose uptake by muscle. 2. The effect of insulin, anaerobiosis and cell poisons on the penetration of isolated rat diaphragm by sugars. Biochem. J. 70, 501-508 (1958)

14. Segal, S., Blair, A., Weinberg, A.: In vitro effects of salicylate on carbohydrate metabolism. Metabolism 9, 1035-1046 (1960)

15. Saleb, S., Kbayyal, M.T., El Masri, A.M., Ghazal, A.M.: Effect of acetylsalicylic acid and phenylbutazone on glucose absorption in vitro. Metabolism 18, 599-605 (1969)

16. Lutwak-Mann, C.: Effect of salicylate and cinchophen on enzymes and metabolic processes. Biochem. J. 36, 706-728 (1942)
17. Winters, R.W., Morrill, M.F.: Carbohydrate metabolism in experimental salicylism. Proc. Soc. Exp. Biol. Med. 88, 409-411 (1955)

18. Woods, H.F., Stubbs, W.A., Johnson, G., Alberti, K. G. M. M.: Inhibition by salicylate of gluconeogenesis in the isolated perfused rat liver. Clin. Exp. Pharmacol. Physiol. 1, 535-540 (1974)

19. Vallecorsi, G. F., Zucchini, M., Cinelli, P., Rocca, M.: Effetti dell'acido acetilsalicilico sulla utilizzazione periferica del glucosio. Arch. Ricambio 28, 3-7 (1964)

20. Carlson, L.A., Ostman, J.: Effect of salicylates on plasmafree fatty acids in normal and diabetic subjects. Metabolism 10, 781-787 (1961)

21. Gilgore, S.G., Rupp, J.J.: Response of blood glucose to intravenous salicylate. Metabolism 10, 419-421 (1961)

22. Micossi, P., Pontiroli, A. E., Tamay, R., Baron, S. H., Lengel, F., Foà, P. P.: Serum glucose, insulin and pancreatic glucagon responses to glucose following aspirin treatment. IX. Congress of the Int. Diabetes Fed., p. 193. Amsterdam: Excerpta Medica Congress Series 1976

23. Field, J. B., Boyle, C., Remer, A.: Effect of salicylate infusion on plasma insulin and glucose tolerance in healthy persons and mild diabetics. Lancet 1967 I, 1191-1193

24. De Coek, N.M.: The effect of aspirin on glucose tolerance tests. Med. J. Aust. 18, 813-815 (1967)

25. Farris, R. K., Tapper, E.J., Powell, W.D., Morris, S.M.: Effect of aspirin on normal and cholera toxin-stimulated intestinal electrolyte transport. J. Clin. Invest. 57, 916-924 (1976)

Received: October 31, 1977,

and in revised form: January 12, 1978

Dr. Dario Giugliano

Istituto di Patologia Speciale Medica

I Policlinico

Pzza L. Miraglia

Napoli, Italy 